\title{
Evaluation of progress with using community conversation as a strategy to encourage district level abandonment of female genital mutilation and/or cutting in 10 districts in Ethiopia
}

\author{
Authors: \\ Ellen Alem ${ }^{1}$ \\ Emezat Hailu ${ }^{2}$ \\ Haile-leul Siyoum ${ }^{3}$ \\ Ibrahim Sesay ${ }^{1}$ \\ Lulit Mitik ${ }^{2}$ \\ Maki Suyama $^{1}$ \\ Martha Kibur ${ }^{1}$ \\ Roger Pearson ${ }^{1}$

\section{Affiliations:} \\ ${ }^{1}$ UNICEF, Addis Ababa, \\ Ethiopia \\ ${ }^{2}$ Centre for Development \\ Consulting, Addis Ababa, \\ Ethiopia
}

${ }^{3}$ Ministry of Women, Children and Youth Affairs, Addis Ababa, Ethiopia

Correspondence to: Maki Suyama

Email:

msuyama@unicef.org

Postal address:

United Nations Children's Fund, UNICEF House, P.O. Box 1169, Addis Ababa,

Ethiopia

Dates:

Received: 01 Mar. 2013

Accepted: 20 Aug. 2013

Published: 03 Oct. 2013

How to cite this article: Alem, E., Hailu, E., Siyoum, H., Sesay, I., Mitik L., Suyama, M., et el, 2013, 'Evaluation of progress with using community conversation as a strategy to encourage district level abandonment of female genital mutilation and/or cutting in 10 districts in Ethiopia', African Evaluation Journal 1(1), Art. \#11, 10 pages. http://dx.doi org/10.4102/aej.v1i1.11

Read online:
Background: Female genital mutilation and/or cutting (FGM/C), whilst widespread, is declining in Ethiopia; 81\% of 45-49-year-old women were circumcised in a 2005 survey, and 62\% of 15-19-year-olds.

Objectives: This evaluation examined progress in abandoning FGM/C in ten woredas (districts) where strategy based on the social convention theory had led to official declarations of abandonment and assessed if the strategy could accelerate the declining trend of the FGM/C practice in Ethiopia.

Method: Quantitative and qualitative instruments collected data from a document review, a household survey (1275 households), in-depth and key informant interviews and focus group discussions.

Results: Overall, there were encouraging results in terms of awareness creation and behavioural change to some extent. Sixty-nine percent of women and $41 \%$ of girls interviewed perceived a decline in the practice (range $40 \%-90 \%$ ) after the declaration. Seventy-six percent of women said they would not circumcise girls in the future. The involvement of influential people such as religious leaders, elders, health extension workers, and law enforcement officials in the teaching contributed immensely to the awareness creation. However, some districts reports indicated the practice had gone underground. The costs of facilitating the strategy varied from USD 3 to 7 per person, with better results where costs were higher. The abandonment events tended to cost around $25 \%$ of total costs, an area where cost efficiency can be improved.

Conclusion: The evaluation has informed the dialogue around the development of the country's first national budgeted strategy that aims to accelerate the abandonment of all harmful traditional practices.

L'évaluation des progrès réalisés en termes de conversation avec la communauté en tant que stratégie d'incitation à l'abandon des mutilations génitales féminines/excision dans $\mathbf{1 0}$ districts éthiopiens

Présentation: La mutilation génitale féminine et/ou excision (MGF/E) est globalement en baisse en Éthiopie: dans une étude réalisée en 2005, elle concernait $81 \%$ des femmes âgées de 45 à 49 , contre $62 \%$ des femmes de 15 à 19 ans.

Objectifs: Cette évaluation se penche sur les progrès réalisés en matière d'abandon des pratiques de MGF/E dans dix woredas (districts), où une stratégie fondée sur la théorie des conventions avait donné lieu à des déclarations officielles d'abandon et avait permis d'évaluer si la stratégie pouvait accélérer la diminution des pratiques de MGF/E en Éthiopie.

Méthode: À l'aide de divers instruments, des données ont été recueillies à partir d'une étude documentaire, d'une enquête auprès des ménages (1275 ménages), d'entretiens en profondeur avec des informateurs clés et des discussions de groupe.

Résultats: On a noté des résultats encourageants en termes de sensibilisation et de changement de comportement. Soixante-neuf pour cent des femmes et $41 \%$ des filles interrogées percevaient une diminution de la pratique (fourchette de $40 \%$ à $90 \%$ ) après la déclaration. Soixante-seize pour cent des femmes affirmaient qu'elles ne feraient pas exciser leurs filles. L'implication de personnes d'influence, comme des chefs religieux, des anciens, des agents de santé et des agents de la force publique a fortement contribué à la sensibilisation. Les rapports sur certains districts font cependant état d'un passage de la pratique à la clandestinité. Le coût associé à la facilitation de la stratégie variait entre 3 à 7 USD par personne, les résultats les meilleurs ayant été obtenus dans la fourchette de coûts la plus élevée. Les cas d'abandon correspondaient à environ $25 \%$ du total des coûts, un point qui pourrait être amélioré.

Conclusion: L'évaluation a permis d'informer le dialogue sur l'élaboration de la première stratégie nationale budgétisée destinée à accélérer l'abandon des pratiques traditionnelles préjudiciables.

Copyright: (C) 2013. The Authors. Licensee: AOSIS OpenJournals. This work is licensed under the Creative Commons Attribution License. 


\section{Introduction}

The term harmful traditional practices (HTPs) refers to practices and cultures which affect the health and wellbeing of women (UNICEF Innocenti Research Centre 2009). HTPs are believed to be caused by the inferior position given to girls and women in society and therefore are another manifestation of discrimination against women.

In Ethiopia, over 80 kinds of HTPs are practiced in different regions (National Committee on Harmful Traditional Practices of Ethiopia 1997). These practices adversely affect the physical as well as mental health of the victims. One of the widely practiced HTPs is female genital mutilation and/ or cutting (FGM/C).

A study of the situation in Egypt, Ethiopia, Kenya, Senegal, Sudan and South Sudan concludes that FGM/C is conducted mainly because it represents the girl's chastity or morality, thus the girl who is cut is considered to be appropriate for marriage (UNICEF Innocenti Research Centre 2010). It is estimated that more than 125 million women and girls in 29 countries in Africa have undergone FGM/C, of which 23.8 million are in Ethiopia (UNICEF 2013).

In Ethiopia, FGM/C is practiced in both Muslim and Christian communities (Ministry of Finance and Economic Development and United Nations Ethiopia 2012). It is deeply embedded in culture. Various forms are practiced, including removing the tips of the clitoris, partial or total removal of the clitoris and labia and sewing together of the two sides (infibulations), which is the severest type of FGM/C. As there are variations in the practice, the age at which FGM/C takes places varies from region to region. In some, it is practiced at infancy, whilst in others it is practiced at the age of 6-9 years, and still in others it happens at the young age of 15-17 years just prior to marriage. Cultural reasons, religion and societal pressure appear to justify the practice.

Ethiopia has adopted internationally binding instruments such as the Convention on the Elimination of All Forms of Discrimination against Women (CEDAW), which requires states to take action towards changing the underlying causes for discrimination with a view to eliminating HTPs amongst other prejudicial practices. At the national level, the constitution of the country extends. At the national level, the constitution of the country extends women the guarantee to be free from HTPs and prohibits such acts. All laws, stereotyped ideas and customs which oppress women or otherwise adversely affect their physical and mental well-being are prohibited. The prohibition is effected through implementing legislation such as the criminal code of the country which gives a non-exhaustive list of acts that constitute HTPs based on the most prevalent types in the country.

FGM/C in Ethiopia is declining significantly at the national level based on data from national surveys. According to the Ethiopia Demographic and Health Survey of 2005, the national prevalence of FGM/C amongst people aged $45-49$ stood at $81 \%$, whilst it was $62 \%$ for $15-19$-year-olds (Central Statistical Agency [CSA] and ICF International 2006). This indicates that fewer people in younger generation experienced FGM/C. The 2011 Ethiopia Welfare Monitoring Survey could complement this tendency. It found that fewer than $25 \%$ of $0-14$-year-olds were cut (CSA 2011). Moreover, the pace of the decline over generations in Ethiopia is much faster when it is compared with the surrounding countries. For example, in Somalia 99\% of women aged $45-49$ and $97 \%$ of girl aged 15-19 underwent FGM/C, in Djibouti 94\% and $90 \%$ respectively, and in Sudan $89 \%$ and $84 \%$ respectively (UNICEF 2013).

For several years, UNICEF Ethiopia and its partners have been supporting the government of Ethiopia to encourage local level declaration of abandonment of FGM/C through the social convention theory strategy advocated by UNICEF and UNFPA. The aim of helping to implement the strategy was to help accelerate the secular trend described above. The evaluation of the programme was conducted by UNICEF in collaboration with the government of Ethiopia in 2012 in ten self-declared woredas (a woreda is the third administrative level in Ethiopia below federal and regional and is akin to a district). These woredas were located within the three regional states of Afar, Benishangul Gumuz, and Southern Nations, Nationalities, and People's Region (SNNPR) and the capital city, Addis Ababa. Each woreda consists of a different number of kebeles (a kebele is the administrative level under woredas) and the geographical characteristics of the kebeles varied. The evaluation aimed at assessing to what extent the strategy does indeed accelerate abandonment of FGM/C at the local level, what the total costs were by local geographical area, and thus to what extent the strategy was worth investing in to move forward as a way of accelerating abandonment. Lessons learned from the evaluation not only help to fine-tune the social convention theory strategy, but will also contribute to the global discourse on the extent to which the application of this strategy can accelerate secular trends for HTP abandonment.

\section{Description of the programme strategies}

The strategy advocated by UNICEF and UNFPA was adapted for the case of Ethiopia. Its theoretical foundation is social convention theory, which, when applied in the context of FGM/C, states that 'in communities where FGM/C is widely practiced, no single family would choose to abandon the practice on its own because it would affect the marriageability of its daughters' (UNICEF Inncocenti Research Centre 2010: 6). According to the theory, this is described as an equilibrium state as no family has the incentive to move away from the expectation of cutting. If however, all families in a community choose not to cut their daughters, cutting will no longer be the social norm and not cutting will become the equilibrium state. Thus, the strategy aims to convince all families within a community to move from the equilibrium state of cutting to a state of not cutting. The major focus of the strategy is 
to use intensive community dialogues, enabling community members to reflect on their own regarding harmful practices and thus eventually to reverse the social convention. The main instrument employed to bring about social change is the creation of opportunities for community conversation on FGM/C. The strategy is based on consultation rather than condemning the conventions as harmful. At a certain point, the community is encouraged to come up with its own regulations or rules on how to address FGM/C and the woreda (district) administration organises an event where a declaration of abandonment across the district is made when it is judged that sufficient sub-woreda-level discussions have taken place. Declaration is considered to be a starting point of abandonment of FGM/C (Toubia \& Sharief 2003) and there is an evidence, for example in Senegal (Diop et al. 2004 in Shaaban \& Harbison 2005), that the declaration led to a significant decrease in FGM/C practice.

Several studies (Shaaban \& Harbison 2005; UNICEF 2013) acknowledged that religious leaders or other influential persons are quite effective allies for helping to accelerate the abandonment of FGM/C because they have power to convince the community. Apart from community conversations, the strategy focuses also on dialogue with religious leaders, health workers, and law enforcement officers to teach and raise awareness. Targeting local religious leaders with a view to turning them into allies especially helps to correct the people's misconception that FGM/C practice is supported by religion (UNICEF 2013). The following activities are implemented as part of the overall approach: teaching about the harmful effects of FGM/C; teaching through interpreting the scriptures and clarifying that religion does not require the circumcision of females; leading and enforcing the campaign of ostracising those who break the declaration, including practitioners; and giving their blessing and encouraging practitioners to undertake an oath in front of religious leaders not to practice anymore. In the religious approach, consensus or agreement amongst religious leaders on the stand of the Quran or the Bible on FGM/C is important.

Targeting health professionals is another element of the strategy. The aim is to engage health professionals in communicating the adverse effects of FGM/C on health (UNICEF 2013). Health extension workers (HEWs) and secondary school leavers, with a year of basic training followed by modular follow-up and a salary, teach community members (two HEWs ideally serve 5000 people) on the adverse health impacts of FGM/C through door-todoor teaching and community conversations; provide preand post-natal services including counselling and registering uncircumcised new-born girls.

Engaging the support of law enforcement officers is also thought to be effective in terms of discouraging people from supporting FGM/C practice (UNICEF 2013). The formal legal system and the informal/traditional system of justice administration are both enrolled. A thorough discussion is conducted with elders and religious leaders in order to distinguish the areas where they can or cannot properly intervene. The following approaches are used for the formal justice administration system: teaching to raise legal awareness about the illegality of FGM/C; punishing perpetrators; increasing accessibility of law enforcement bodies; accelerating the legal process whereby the police act as prosecutor and investigator at the same time; and establishing circuit courts that move into the rural areas. Together with health workers, the importance is taught of preserving evidence by taking victims to health institutions quickly.

UNICEF (2013) found that less educated women in Ethiopia tend to think FGM/C should be continued compared with the women with higher education. Therefore, compulsory education especially girls' education could be considered as a part of the strategy. In addition, schools are used in establishing and strengthening girls' clubs; empowering female teachers to report FGM/C activity to relevant authorities; teaching children about FGM/C at schools, and providing cell phones for purposes of contacting authorities if and when circumcision is to take place; and using school clubs with membership of boys and girls to intervene when their younger siblings or neighbours' children are about to be circumcised.

When FGM/C is abandoned in the community, the practice could go underground. This tendency was found in some studies (for example Toubia \& Sharief 2003; UNICEF 2013). Community structures are used for the reporting to prevent the practice from going underground. For example, in most woredas in the SNNPR and Guba, they are referred to as HTP committees and are composed of religious leaders, youth representatives, leaders from Women's Associations, as well as the kebele administration. In Afar, they formed a part of the community police structures. In other woredas, Women's Associations play the role of teaching and reporting.

To pursue the overall strategy, strong political commitment and leadership is crucial. It includes allocating adequate budgets; laying out structures that will enable all sections of society to be reached; putting police officers in each kebele; educating practitioners and training them in other skills and facilitating other forms of income generation; and lastly, ensuring that leaders serve as role models by not engaging in the practice of FGM/C and/or by encouraging others not to practice FGM/C. Furthermore, strong coordination of the activities of various stakeholders, such as government sectors, NGOs and community-based organisations are necessary.

\section{Methods \\ Sampling frame and technique}

For the purpose of the 2007 population and housing census in Ethiopia, all kebeles in each city were delineated into census enumeration areas (EAs). The primary sampling units 
were census EAs, whilst secondary sampling units were the households to which the survey questionnaires were administered.

To avoid having to weight the household level data, selection of the predetermined number of EAs from each group was performed by using a probability proportional to size sampling technique. This was carried out because the size of households in each EA varies. The total number of sampled EAs was fixed at 49.72. Then, to determine the total household sample size, the $95 \%$ confidence interval, $5 \%$ tolerable error, the prevalence of the risk factors related to HTPs accounted for by the target population, design effect of 1.5 and $10 \%$ adjustment for the non-response rate were taken as an input.

The formula to calculate the total household sample size was:

$$
\mathrm{nHH}=[4(\mathrm{r})(1-\mathrm{r})(\mathrm{f})(\mathrm{re})] /[(\mathrm{dr}) 2(\mathrm{p})(\mathrm{nh})]
$$

The following parameters were used:

- Number of households in the sample (nHH)

- The prevalence of the risk factors accounted for by the target population (r)

- Target group proportion: number in target group / total population (p)

- Relative precision around the proportion $\mathrm{p}(\mathrm{d})$

- Design effect (f)

- Response (re) (1/response rate, e.g. for $90 \%$ response rate, use 1.1)

- Average household size (nh).

Based on the calculation, the total household sample size was determined as 1275 (Table 1). Then the total number of households (1275) was divided by the total number of EAs (49.72) and the sample household size was fixed at 25 households per EA. Generally, there is some similarity amongst the households residing in a cluster (EA). Results from different socio-economic surveys conducted by the Central Statistical Agency (CSA) show that households within the same cluster (EA) have a high intra-cluster correlation coefficient, which implies similarities in characteristics. Using this information, it was decided that data obtained from 25 sample households was representative of the total households residing in an EA (cluster). Other factors such as time and resource constraints were also taken into consideration when fixing the sample size per EA.

The next step was to select sample households within each EA. From each sample EA, 25 households were selected and the number of total households was given on the EA map. Since the total number of households in each sample EA was known, selection of 25 sample households from each cluster (EA) was performed simply by using systematic random sampling. The sampling interval $(n)$ for each EA was determined by dividing the total number of households in the sample EA by 25 . The sample start was obtained by taking a random number between 1 and $n$. Then, every nth household was sampled by canvassing each housing unit in a sampled EA until the 25 households were selected. In each household, one woman above 19 years old, one man above 19 years old, and one teenage girl were interviewed.

A total of 1275 households were interviewed in the 10 woredas. At woreda level, 450 respondents were interviewed in Alaba, 600 in Cheha and Dale, 525 in Guba, Kolfe and Yeka, and 150 in the four woredas of Afar region (Table 2 a and $b$ ). The following stakeholders were interviewed in the course of the evaluation:

- Mothers and/or primary care givers of circumcised daughters,

- Teenage girls

- Women above 19

- Men above 19

- Community leaders and/or elders

- Religious leaders

- Woreda officials

- Members of law enforcement organs including the police, prosecutors and justice administrators or judges

- Bureau of Women, Children and Youth Affairs (BOWCYA) officials in the regions and Federal Ministry of Women, Children and Youth Affairs (MOWCYA) officials

- UNICEF staff in Addis Ababa and in regional offices where the woredas are located

- Members of community protection mechanisms

- Health extension workers

- Staff of fixed health facilities.

TABLE 1: Sample size in the selected woredas.

\begin{tabular}{|c|c|c|c|c|c|c|}
\hline Region & Zone & Woreda (i) & $\begin{array}{l}\text { Target group } \\
\text { proportion in \% }\end{array}$ & $\begin{array}{l}\text { Prevalence rate } \\
(r)(2005 \text { DHS }) \text { in \% }\end{array}$ & $\mathrm{nHH}$ & Sample size EAs \\
\hline Afar & Zone1 & Elidar & 24.37 & 91.7 & 36 & 2 \\
\hline Afar & Zone3 & Amibara & 24.75 & 91.7 & 46 & 2 \\
\hline Afar & Zone3 & Awash Fentale & 27.06 & 91.7 & 43 & 2 \\
\hline Afar & Zone3 & Gewane & 25.28 & 91.7 & 35 & 2 \\
\hline Benishangul Gumuz & Metekel & Guba & 26 & 67.6 & 194 & 7.36 \\
\hline SNNPR & Guraghe & Cheha & 24.79 & 71 & 198 & 6.72 \\
\hline SNNPR & Sidama & Dale & 23.03 & 71 & 191 & 7.24 \\
\hline SNNPR & Hadiya & Alaba & 25.44 & 78.5 & 170 & 6.28 \\
\hline Addis Ababa & 14 & Kolfe Keranio & 29.85 & 65.6 & 177 & 6.72 \\
\hline Addis Ababa & 14 & Yeka & 28.76 & 65.6 & 185 & 7.4 \\
\hline Total & - & - & - & - & 1275 & 49.72 \\
\hline
\end{tabular}

$\mathrm{nHH}$, number of households; EAs, enumeration areas; DHS, district household survey. 
TABLE 2a: Total sample size: $1275 \mathrm{HH}$ (three respondents from each household/s).

\begin{tabular}{lcc}
\hline Type of respondent & No. of respondents & Sex \\
\hline Men & 1275 & Male \\
Women (above 19) & 1275 & Female \\
Teenagers & 1275 & Female \\
\hline Total & $\mathbf{3 8 2 5}$ & -
\end{tabular}

TABLE 2b: Sample size.

\begin{tabular}{lcccc}
\hline Woredas & \multicolumn{4}{c}{ Type of respondent } \\
\cline { 2 - 5 } & Women & Men & Teenagers & Total \\
\hline Alaba & 150 & 150 & 150 & 450 \\
Cheha & 200 & 200 & 200 & 600 \\
Dale & 200 & 200 & 200 & 600 \\
Guba & 175 & 175 & 175 & 525 \\
Kolfe & 175 & 175 & 175 & 525 \\
Yeka & 175 & 175 & 175 & 525 \\
Elidar & 50 & 50 & 50 & 150 \\
Amibara & 50 & 50 & 50 & 150 \\
Awash Fentale & 50 & 50 & 50 & 150 \\
Gewane & 50 & 50 & 50 & 150 \\
\hline
\end{tabular}

\section{Data collection instruments}

A set of quantitative and qualitative instruments was employed to collect data for carrying out the proposed assignment. The quantitative method consisted of administering close-ended questionnaires. The qualitative approach included in-depth and key informant interviews (KIIs) as well as focus group discussions (FGDs). The implementation of the quantitative and qualitative instruments was preceded by a thorough desk review.

In the survey, the respondents were asked to provide information on their knowledge, attitude and practice with regards to $\mathrm{FGM} / \mathrm{C}$, whereas health-related information, including data and testimonials were elicited from health facilities and health workers. Finally, indicators related to administration of the law and/or the declaration, such as reporting to the police, cases seen by public prosecutors and similarly reports to other parts of the government machinery such as the Women, Children and Youth Affairs offices were used.

\section{Desk review}

A thorough review of documentation was conducted including all available documents on the practice and abandonment of FGM/C. Further, UN joint programme documents on Leave No Woman Behind and Gender Equality and Empowerment of Women which have important components on HTPs were consulted.

\section{Quantitative survey}

The quantitative approach consisted in administering closeended questionnaires at household level. Specific questions were designed for women and men above 19 years old and teenage girls. Survey instruments were pre-tested in a small sample of groups and, based on the pre-test results, were revised accordingly before the actual implementation. The main questions asked were regarding awareness on the declaration of abandonment, changes in the practice of FGM/C after the declaration, and future intention to conduct FGM/C on their daughters or grand-daughters.

\section{Qualitative survey}

This approach was designed in such a way that it could complement the information gathered through the quantitative approach and the desk review. The qualitative instrument was composed of a set of open-ended and semi-structured questions for key informants and in-depth interviews as well as FGDs.

\section{In-depth and key informant interviews}

A series of semi-structured interview instruments that reflect the range of issues and questions contained in the evaluation were designed for woreda officials, Bureau of Women, Children and Youth Affairs (BOWCYA) officials, Ministry of Women, Children and Youth Affairs (MOWCYA) officials, members of law enforcement organs, members of community protection mechanisms, health extension workers, staff of fixed health facilities, community leaders, and religious leaders. These interviews included lengthy and detailed discussions on stakeholders' opinions and knowledge on FGM/C. Some success stories were extracted from the findings of the interviews.

\section{Focus group discussions}

In total, 102 FGDs were conducted (two per kebele: one with women above 19 years of age and another with teenage girls). Talking to stakeholders in groups provided a uniquely valuable opportunity to elicit new information, and triangulate data or check impressions gained by others. Group processes can take advantage of interactions within the group to stimulate participation and generate new materials. The main questions asked were whether the participants support FGM/C practice, the types of ongoing interventions to abandon FGM/C, and the challenges to abandon FGM/C in the woreda. FGDs differ from KIIs as they afford more debate and follow-up and are conducted in a group setting.

\section{Data collection}

The team was composed of supervisors and data collectors. The supervisors were responsible for obtaining permission to conduct the survey at the selected sites and communicating with the coordinator of the overall study to report on the progress made and challenges faced. The data collectors went through training and field testing before deployment for the actual data collection. The instruments were pre-tested, and were later refined based on pre-test results. Finally, following the pre-test and revision, the data collection instruments were finalised.

\section{Data analysis}

Data analysis focused on addressing the general as well as the specific objectives of the evaluation. Different analytical procedures were employed in accordance with the nature 
of the variables involved. The data collected through the different tools were used to feed into the analytical framework.

\section{Ethical considerations}

The evaluation followed UNICEF guidelines on the ethical participation of children. All unacceptable methods were excluded with the consultation of steering committees before the field work started. All participants in the evaluation were fully informed about the nature and purpose of the study and their requested involvement.

\section{Limitations}

Statistical indicators would have been ideal for evaluating change and measuring trends in the practice of FGM/C. However, there was no base line which the team could rely on and this prevented measurement of the impact of efforts to eliminate HTPs. Furthermore, in some woredas, the cost analysis was not comprehensive for different reasons. Unit cost was not analysed in Addis Ababa and SNNPR due to the unavailability of data on population size covered by the programme and frequency of community meetings. In the Elidar woreda in the Afar region, only the total expenditure was available.

\section{Findings}

\section{Evidence on the extent of female genital mutilation and/or cutting}

Adult women and teenagers were asked about their personal experiences with regard to FGM/C. With the exception of Kolfe and Yeka where the percentage of circumcised women was quite low, the overwhelming majority of adult women, $80 \%$ on average, in all the woredas had undergone circumcision (Figure 1). This picture is quite different when it comes to teenagers. Overall, the rate of circumcision was much lower, with 35\% (Figure 2). There appears to be a general decline in the practice across the sample areas, mirroring the trends revealed by nationwide surveys, which found a lesser rate of circumcision amongst the younger generation. It is important to note also that quite a significant percentage of the teenagers in Guba, Yeka, Kolfe, as well as all the woredas in Afar, replied that they do not know if they have been circumcised. It is very likely that these teenagers were shy to talk about circumcision, hence their choice not to answer directly.

\section{Effect of the declaration}

To adequately assess the prevalence of the practice before and after the declaration of abandonment, the evaluators looked into the level of awareness about the declaration, the trend in the practice after the declaration and future behaviour.

There was a good level of awareness about the declaration to abandon FGM/C amongst adult women, with over $70 \%$ claiming to be aware of the declaration in many of the woredas (Figure 3). It was in Elidar that only $46 \%$ of women claimed to have awareness about the declaration. This is perhaps explained by the relatively recent adoption of the declaration in Elidar. Amongst teenagers, only in Alaba did 70\% of the respondents report knowledge about the declaration, whilst the percentage was much lower in the other woredas with the lowest in Elidar (12\%) (Figure 4). There, results of KIIs as well as FGDs revealed that teenagers did not usually take part in the community conversation, which is the main mechanism employed towards the declaration, because they were regarded as children. It was also revealed that adult women may also lack capacity to participate due to

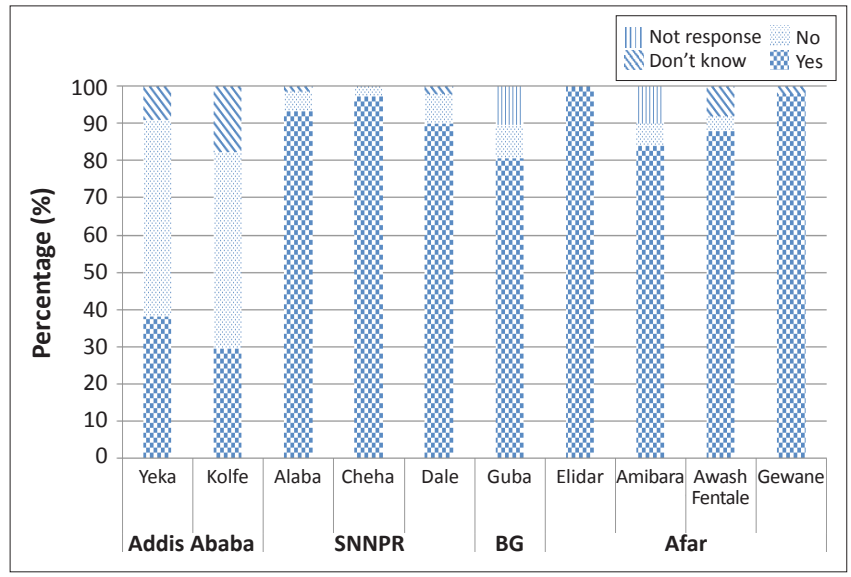

FIGURE 1: Women - Are you circumcised?

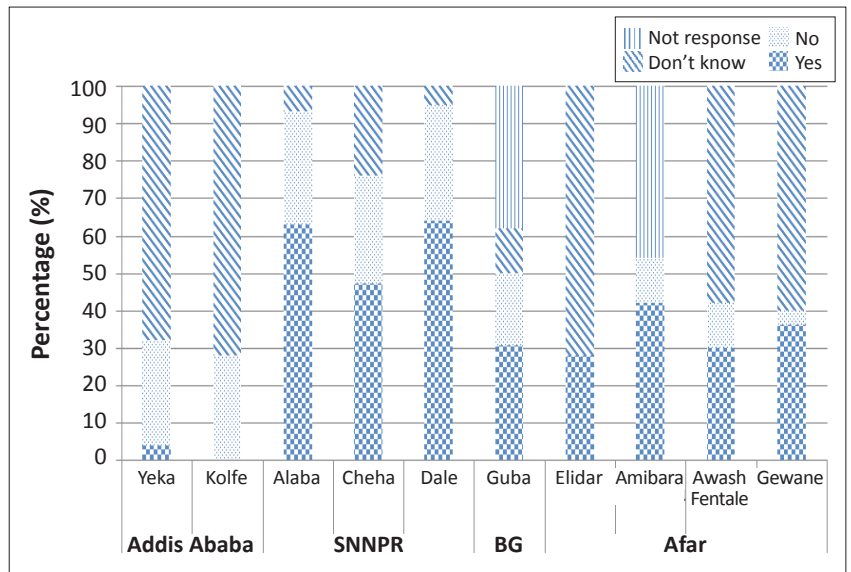

FIGURE 2: Teenagers - Are you circumcised?

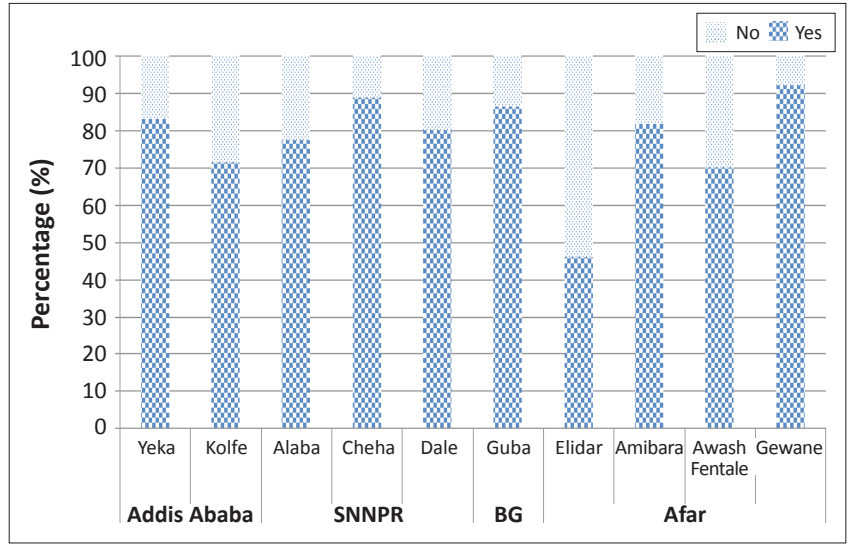

FIGURE 3: Women - Are you aware of the declaration of abandonment of $\mathrm{FGM} / \mathrm{C}$ practice in your woreda? 
work load pressure. Similarly, adult men in some woredas like Guba may not participate as much because community conversations were carried out during the time when they travel across the border for trade purposes.

In all the woredas, the survey results showed a perceived decline in the practice after the declaration. Amongst adult women, $69 \%$ of the respondents believed that the practice had declined after the declaration (Figure 5). The proportion of women who indicated an increase after the declaration was near zero in most woredas with the highest rate at $4.5 \%$ in Guba. For teenagers, $4 \%$ of the girls interviewed perceived a decline after the declaration. For the remaining woredas, a higher percentage of the respondents said they did not know if it had decreased or increased (from $9 \%$ in Dale to $85 \%$ in Yeka) (Figure 6). This finding correlates with the previous finding where the majority of teenagers reported that they were not aware of the declaration; as such, it is not surprising that they could not tell a decrease or otherwise vis-à-vis the declaration. The proportion of teenagers who indicated an increase after the declaration was zero in all woredas.

Although the survey results appeared to indicate a perceived decline, KIIs as well as FGDs for the majority of the woredas showed that the practice appeared to have gone underground

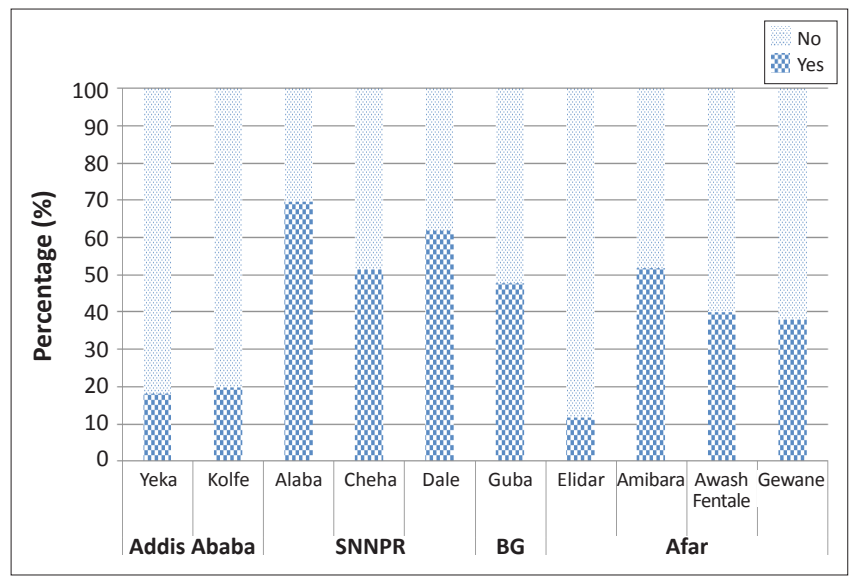

FIGURE 4: Teenagers - Are you aware of the declaration of abandonment of $\mathrm{FGM} / \mathrm{C}$ practice in your woreda?

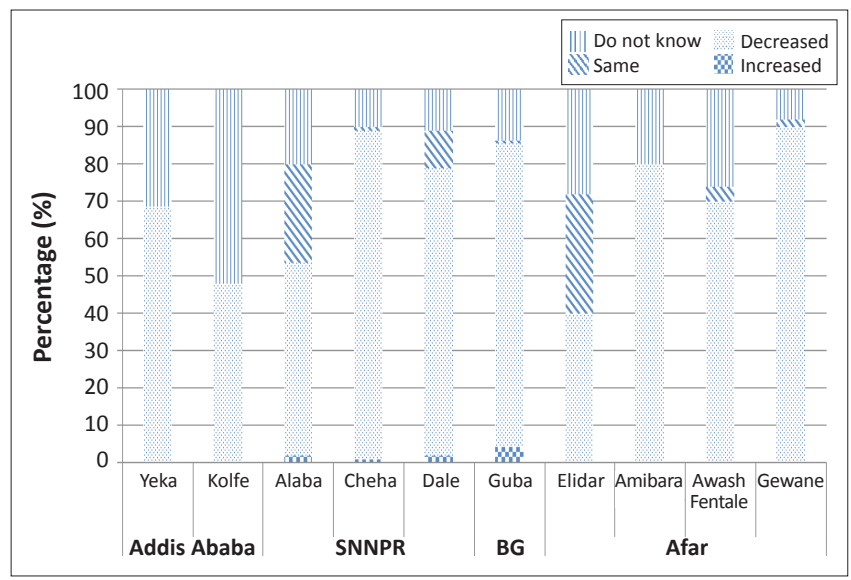

FIGURE 5: Women - In your opinion, has the practice of FGM/C decreased or increased since the declaration of abandonment? and hence the decline may be superficial. For instance in Dale, Alaba, Guba, Gewane, and Awash, it was commonly noted during the KIIs and FGDs that the practice of FGM/C may have gone underground due to fear of reporting and punishment. Furthermore, members of community protection mechanisms and ex-practitioners of FGM/C also revealed that community members who live in distant rural areas still lack awareness, hindering the abandonment of FGM/C in its totality. In some programme woredas, however, community people or Women's Associations and Federations which have mass membership at community level found to be playing an important role in detecting and reporting on underground practices of FGM/C.

The future behaviour of respondents with regards to the practice of FGM/C is a strong indication of the impact of the declaration on the practice. Seventy percent of the respondent women in all woredas stated that they do not intend to circumcise their daughters in the future (Figure 7). The highest percentage of those that claimed they would circumcise their daughters in the future are in Alaba, 31.5\%, and 30\% in Elidar. Culture and religion are given as reasons for the intention to circumcise daughters or girls for whom they are the primary care givers in the future.

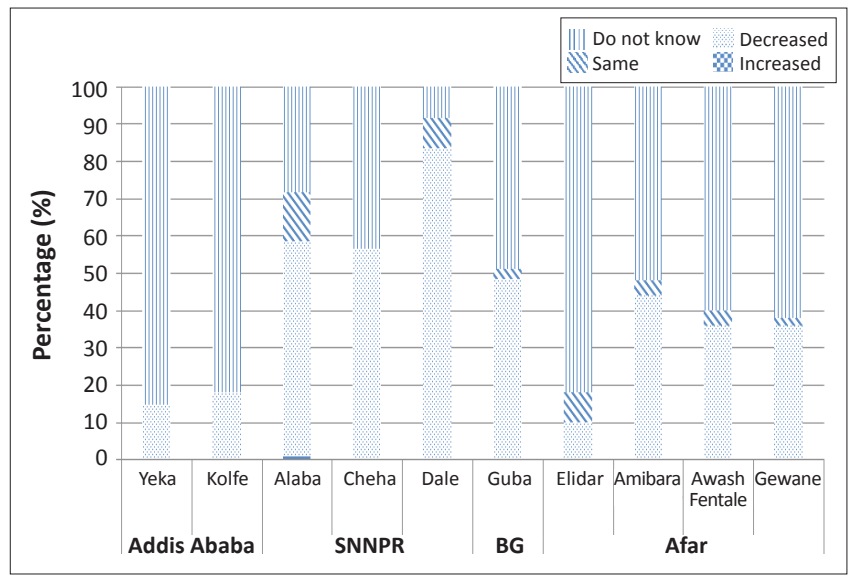

FIGURE 6: Teenagers - In your opinion, has the practice of FGM/C decreased or increased since the declaration of abandonment?

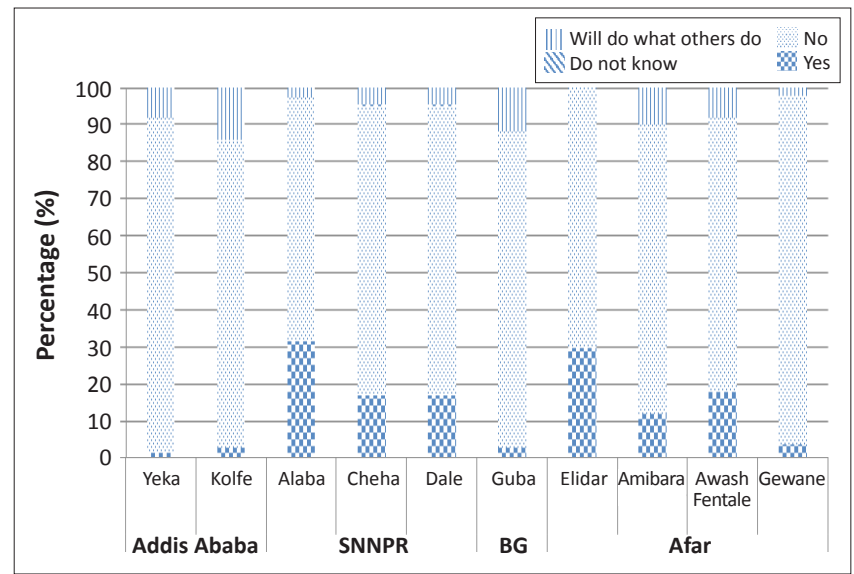

FIGURE 7: Women - Would you circumcise your other daughters (if you have any) or other girls for whom you are the primary care givers? 
Community conversations were the main vehicle amongst other strategies to bring about the declaration and they brought a change in the social norm when they were carried out in a continuous and sustainable manner and reached to many of the kebeles including the remote ones. In some woredas, the process was spearheaded by Women's Affairs offices, for example, Cheha in SNNPR, whilst in others like Afar, by non-governmental organisations (NGOs). The community conversations were conducted continuously and repeatedly, involving as many kebeles as possible in woredas like Cheha before culminating in a declaration. In others like Alaba and Dale of SNNPR as well as in Afar, due to challenges of remoteness of some kebeles and budgetary constraints, the community conversations were not conducted in a sustainable manner. As a result, declarations were made even before reaching many kebeles. Therefore, one can observe that the process that led to the declarations has not been similar in all woredas, and there is no clarity as to what the community conversations that brought about the declarations involved in terms of its frequency, coverage and the number of people that took part.

In terms of actors and participants in the conversation, the involvement of religious leaders and elders, health extension workers, law enforcement officers in the actual teaching contributed immensely to pass on the required message to the community. Their prominent role was managing the community conversations and clarifying that the FGM/C practice is not supported by religion. This was important, as reasons for the perceived decline in FGM/C can be directly linked to religious teachings, adverse health impacts, and to the recognition of illegality, including through the community declaration. Regarding the meeting places, religious gatherings in mosques and churches were considered to be ideal by the community.

There seemed to be awareness about the adverse health effects of FGM/C as a large number of female respondents, both adults and teenagers, gave this as one of the reasons behind the perceived decline in the practice of FGM/C. Women and girls also seemed to be informed that FGM/C is an HTP.

\section{Efficiency of the programme}

Whilst estimating the costs of the repercussions of FGM/C on the health services has been examined (for example by WHO), the cost of implementing the FGM/C abandonment strategy evaluated herein has not previously been calculated. The total expenditure made during the programme implementation period (2007-2011) per woreda varied from USD 19180 to USD 96 821. The total expenditure depended on the size of the target population, the geographical location and the size of the woreda, the length of time that the programme had been implemented, and the level of the prevalence of FGM/C in the woreda. For instance, Addis Ababa, where target woredas are located on the outskirts of the capital city, spent the lowest amount per sub-city from 2007 to 2011, whilst Guba, where the woredas are scattered across rural areas, had the highest expenditure from 2009 to 2011.
The average cost of facilitating the strategy (including project launching, administration and project support, all training, review meetings, micro-assessment of the NGOs, establishment of girls clubs, and monitoring) varied from USD 3 to 7 per person. Where unit costs were higher, more people were aware of the declaration and perceived the decreasing in FGM/C practice in the woreda. The proportion of costs spent on FGM/C abandonment events (including refreshments and distribution of T-shirts and hats) was the highest amongst the activities, ranging between 25\% and $30 \%$ of the total costs.

\section{Challenges}

Interference in law enforcement: The legal process aimed at prevention and punishment of perpetrators of FGM/C is usually affected by the intervention of elders and religious leaders. When these practices are committed, elders and/ or religious leaders intervene in the process through the traditional system of settling disputes. This usually results in pressure on the victim and the family to reconcile, thereby adversely affecting the due process of law.

Weak commitment and leadership and lack of strong coordination: The weak commitment towards the fight against FGM/C is reflected in different ways. These include leaders' participation in FGM/C; lack of adequate budgets and logistical problems in reaching rural and faraway areas; and some kebeles' decision not to sign the declaration despite their neighbours' decision to do so. There is also lack of strong coordination amongst the various stakeholders working on FGM/C. For instance, in some cases, there is lack of coordination amongst the woreda administration and the community, who must be engaged for buy-in to occur. The fact that there is no coordination amongst the different woredas leads people to move from one woreda to another in order to practice FGM/C.

Weak enforcement of the law: Although FGM/C is a prohibited act, there is no adequate legal protection of victims by the law and there is weak punishment meted out to perpetrators. This weakens the preventive effect of the law, and does not encourage deterrence amongst practitioners.

Deep-rooted culture and religious beliefs: Because the practice of FGM/C is deeply rooted in cultural and religious beliefs, it is very difficult to bring about attitude change. The problem is exacerbated by social and peer pressure amongst girls, which leads to despair amongst women that they will not get married if they are not circumcised. For example, this is true in Dale where some of the teenage respondents stated that they are in favour of the practice because they do not want to be ostracized by their peers and the community, and at the same time, they can more easily find their marriage partners. One of the teenage FGD participants for example stated, 'I have not been circumcised but I feel ashamed that I am not circumcised.'

Belief amongst men that FGM/C is beneficial practice: There is a belief amongst men that the practice of FGM/C is beneficial. 
The findings from the different woredas showed that a good proportion of men, for example about $60 \%$ of respondents in Alaba and 39\% in Amibara, considers FGM/C to have advantages in terms of getting social acceptance. There is also a preference to marry circumcised girls, for instance $63 \%$ in Alaba, and $40 \%$ in Amibara. Others have indicated that the practice is beneficial in preserving a girl's virginity and thereby increasing her marriage prospects.

\section{Conclusion}

The findings highlighted strategies that have proven to be efficient in fighting FGM/C. Although it is probably too soon to ascertain a sustained decline in the practice of FGM/C in the ten woredas evaluated, and there was the limitation that there was no base-line data for comparison, to some extent, there are encouraging results in terms of awareness creation and behavioural change.

Looking at the overall picture, the fact that a lesser proportion of teenagers compared to adult women were circumcised in most woredas may be an indication that there is some decline in the practice of FGM/C. With regard to the trend in the practice of FGM/C, the general findings showed that FGM/C has not increased since the declaration of abandonment in most woredas; instead, respondents perceived a declining trend. There was consensus that FGM/C is no longer practiced in the open, and that it is gradually being abandoned. However, most respondents indicated that in some places, it is now an underground practice, especially in remote rural areas. This needs further attention from community leadership.

The adverse health effects of FGM/C and recognition that it is a harmful practice is now common knowledge amongst women and teenagers. Men seemed to show some awareness of this as well. A specific approach needs to be designed to target men, as findings have shown that one of the reasons behind female circumcision is the prospect of marriage, and a significant number of young girls are requested to undergo FGM/C at an advanced age without seeking their parents' approval.

In addition, there appeared to be a certain level of motivation of attitudinal change arising from increased awareness about the adverse effects of FGM/C. Overall, a significant share of respondents did not have the intention of circumcising their daughters in the future. There also seemed to be increased awareness amongst men. Most men did not wish to see the practice continued. There should be a follow-up survey to confirm that this change in awareness will be maintained and actually contribute to reduce FGM/C in the future.

It appears that regular and repeated awareness-raising interventions in all sections of the society that stress the detrimental impacts of FGM/C in addition to encouraging communities to make a declaration of abandonment may be a first step towards changing attitudes and practices. The involvement of influential people in the community such as religious leaders, elders, health extension workers and law enforcement officials is critical for the community conversations. These strategies have potential to increase awareness and pave the way towards attitudinal change that may in turn result in the abandonment of FGM/C.

The overall FGM/C abandonment strategy is intensive, and requires a strong and high quality field monitoring presence. Those investing in the abandonment approach using this strategy need to be realistic regarding the inputs and time line required to implement, ensuring that cash and field monitoring staff time are budgeted. Similarly, if this strategy is an element of national effort to combat FGM/C, the inputs for scale-up need to be realistically budgeted for. Costs in the ten woredas varied from approximately USD 3-7 per capita, spread out over a period of three years, with costs being higher in the larger more remote woredas.

One aspect where costs can be saved is clear. It takes three years to reach a point where abandonment is declared, yet the ceremony itself, with its attendant refreshments and distribution of T-shirts and hats in the woreda capital, amounts to between $25 \%$ and $30 \%$ of total costs. At the same time, the household survey revealed that the more remote parts of the woredas are often neglected. It may well be that budgets are best deployed in making the extra effort needed to reach the most remote areas or to reduce the unit costs per woreda, allowing for a greater geographical spread. On the other hand, if the media exploit these events, the ripple effects on the larger dialogue about FGM/C going on in society might mean the investment in the event would help with further acceleration.

Civil servants accountable for leading government efforts to back up the law declaring FGM/C illegal by accelerating abandonment are developing a national strategy with a budgeted action plan. The information from this evaluation is being used to plan the level of resources needed to fund community FGM/C abandonment. The cost of implementing the strategy per woreda is not small. Therefore, there is need to think on how to implement the strategy in a country with more than 800 woredas. Should it be implemented in the most remote woredas where operational costs are higher but prevalence is also at its highest? Should it be implemented in urban centres where cultural change is happening faster but which also serve as early adopting centres to which rural areas look up? These are questions for the national strategy to decide upon.

\section{Acknowledgements}

The authors appreciate the time of the people who agreed to be interviewed in the ten districts chosen for this evaluation from government officials to elders and young girls. We also thank German National Committee for UNICEF and European Commission for their funding for parts of the work evaluated along with core resources from UNFPA and UNICEF. We are also grateful to the steering committee members (Mr Abate Gudunffa (National Committee Against HTPs [EGLDAM]), Mr Admassu Nebebe (Ministry of Finance 
and Economic Development), Mr Berhanu Legesse (UNFPA), Ms Hiwot Gebeyehu (UNICEF Research, Evaluation, Policy and Monitoring section), Ms Mira Ihalainen (UN Women), Mr Sileshi Tadesse (Ministry of Women, Children and Youth Affairs), Ms Tabeyin Gedlu(UNICEFChild Protection section) and Ms Yumi Matsuda (UNICEF Research, Evaluation, Policy and Monitoring section) for their contributions throughout the evaluation process.

The opinions expressed are those of the authors and editors and do not necessarily reflect the policies or views of UNICEF or the government of Ethiopia.

\section{Competing interests}

The authors declare that they have no financial or personal relationship(s) which may have inappropriately influenced them in writing this article.

\section{Authors' contributions}

E.A. (UNICEF Ethiopia) supervised the evaluation process; E.H. (Centre for Development Consulting) and L.M. (Centre for Development Consulting) carried out the field work and drafted the evaluation report; H.S. (Ministry of Women, Children and Youth Affairs in Ethiopia) chaired the steering committee for the evaluation and in this capacity finalised the terms of reference, coordinated the review of findings, and the development of the government's action plan following the evaluation. I.S. (UNICEF Ethiopia), M.K. (UNICEF Ethiopia) and R.P. (UNICEF Ethiopia) helped to draft the terms of reference, contracted and supervised the consultants, reviewed the draft evaluation report, facilitated the development of the action points stemming from the evaluation and the follow-up on the action points. M.S. (UNICEF Ethiopia) developed the literature review for the article and coordinated the team of authors in the development of the article.

\section{References}

Central Statistical Agency and ICF International, 2006, Ethiopia demographic and health survey 2005, Central Statistical Agency, Addis Ababa and ORC Macro, Calverton, MD, viewed 28 February 2013, from http://www.measuredhs.com/ Calverton, MD, viewed 28 February 2013,
pubs/pdf/FR179/FR179[23June2011].pdf

Central Statistical Agency, 2012, Welfare monitoring survey 2011: Statistical report basic population characteristics, education, health, child care and breast feeding vol. I, Central Statistical Agency, Addis Ababa, viewed 28 February 2013, from hol. I, Central Statistical Agency, Addis Ababa, viewed 28 February 2013, from http://www.csa.gov.et/surveys/Welfare_Monitoring_Survey/Welfare_Monitoring SURVEY\%202011\%20VOLUME\%201.pdf

National Committee on Harmful Traditional Practices of Ethiopia, 1997, Baseline survey on harmful traditional practice in Ethiopia, National Committee on Harmful survey on harmful traditional practice in Ethiopia,
Traditional Practices of Ethiopia, Addis Ababa.

Ministry of Finance and Economic Development and United Nations Ethiopia, 2012, Investing in boys and girls in Ethiopia: Past, present and future, UNICEF, Addis Ababa, viewed 28 February 2013, from http://www.unicef.org/ethiopia/ET_ sitan_2012.pdf

Shaaban, L.M. \& Harbison, S., 2005, 'Reaching the tipping point against female genital mutilation', The Lancet 366(9483), 347-349, viewed 23 August 2013, from http:// www.thelancet.com/journals/lancet/article/PIIS0140-6736(05)67003-1/fulltext

Toubia, N.F. \& Sharief, E.H., 2003, 'Female genital mutilation: Have we made progress?', International Journal of Gynecology and Obstetrics 82, 251-261, viewed 23 August 2013, from http://www.sciencedirect.com/science/article/pii/ S0020729203002297\#

UNICEF Innocenti Research Centre, 2009, Ethiopia: A comparative analysis of the social dynamics of abandonment of harmful practices in four locations, Special series on social norms and harmful practices IWP-2009-07, UNICEF Innocent Research Centre, Florence.

UNICEF Innocenti Research Centre, 2010, The dynamics of social change: Towards the abandonment of female general mutilation/cutting in five African countries, UNICEF Innocenti Research Centre, Florence.

UNICEF, 2013, Female genital mutilation/cutting: A statistical overview and exploration of the dynamics of change, UNICEF, New York. 